\title{
An Affective-Motivational Interface for a Pedagogical Agent
}

\author{
Martha Mora-Torres ${ }^{1}$, Ana Lilia Laureano-Cruces ${ }^{1,2,3}$, Fernando Gamboa-Rodríguez ${ }^{4}$, \\ Javier Ramírez-Rodríguez ${ }^{2,3}$, Lourdes Sánchez-Guerrero ${ }^{2}$ \\ ${ }^{1}$ Posgrado en Ciencia e Ingeniería de la Computación, Universidad Nacional Autónoma de México, México City, México \\ ${ }^{2}$ Departamento de Sistemas, Universidad Autónoma Metropolitana-Azcapotzalco, México City, México \\ ${ }^{3}$ Laboratoire Informatique d'Avignon, Université d'Avignon et des Pays de Vaucluse, Avignon, France \\ ${ }^{4}$ CCADET, Universidad Nacional Autónoma de México, México City, México \\ Email: kabhun@yahoo.com.mx, clc@azc.uam.mx, fernando.gamboa@ccadet.unam.mx, \\ jararo@azc.uam.mx, lsg@azc.uam.mx
}

Received October 7, 2013; revised November 8, 2013; accepted November 15, 2013

Copyright (C) 2014 Martha Mora-Torres et al. This is an open access article distributed under the Creative Commons Attribution License, which permits unrestricted use, distribution, and reproduction in any medium, provided the original work is properly cited. In accordance of the Creative Commons Attribution License all Copyrights (C) 2014 are reserved for SCIRP and the owner of the intellectual property Martha Mora-Torres et al. All Copyright (C) 2014 are guarded by low and by SCIRP as a guardian.

\section{ABSTRACT}

This research is framed within the affective computing, which explains the importance of emotions in human cognition (decision making, perception, interaction and human intelligence). Applying this approach to a pedagogical agent is an essential part to enhance the effectiveness of the teaching-learning process of an intelligent learning system. This work focuses on the design of the inference engine that will give life to the interface, where the latter is represented by a pedagogical agent. The inference engine is based on an affective-motivational model. This model is implemented by using artificial intelligence technique called fuzzy cognitive maps.

\section{KEYWORDS}

Affective-Motivational Model; Intelligent Learning System; Pedagogical Agent; Affective Computing; Simulation of Emotions

\section{Introduction}

Intelligent Learning Systems (ILS) conceive the teaching-learning process (TLP) as a partnership between the module tutors, whose interactions with the user are represented by a pedagogical agent $[1,2]$. Therefore, it is necessary to consider a psychological theory of emotion that sustains the necessary motivational affective model to obtain the affective-motivational state of the user. In the psychology of emotion, there are several theories whose fundamental differences relate to the definition and conceptualization of emotion [3]. However, the elements of the emotion definition show some degree of convergence among the different theoretical. The theory of Ortony, Clore, Collins [4], known as OCC theory, specifies a psychological structure of emotions according to personal and interpersonal descriptions of events. Therefore, based on OCC theory, an affective-motivational cognitive structure is developing [5-10] and used in systems with artificial intelligence (AI). In this case, reasoning system is tied to tutor module, so that the pedagogical agent improves the intelligent learning system (ILS) performance.

In order to achieve it, the integration of affective-motivational cognitive structure efficiently binding to the TLP is necessary.

This paper is organized in sections. Section 2 explains the OCC theory underlying the affective-motivational cognitive structure, Section 3 explains the AI technique called Fuzzy Cognitive Maps (FCM), which are used to represent the affective-motivational model (based on the affective-motivational cognitive structure), Section 4 explains the pedagogical agent interface of ILS, Section 5 explains the affective-motivational cognitive structure design, Section 6 explains the ILS tests and results, finally we find Section 7 with conclusions. 


\section{Emotions According to the Theory of Ortony, Clore and Collins (OCC)}

OCC theory proposes a general structure which specifies that there are three main kinds of emotions, the result of focusing on each of the three highlights of the world:

- Events and their consequences

- Agents and their actions.

- Pure and simple objects.

This establishes the evaluation criteria:

- Goals to evaluate events.

- Rules for evaluating the action of the agents.

- Attitudes for evaluating the objects.

There are three main kinds of emotions specified:

- Emotions based on events: specifying the goals related to the events.

- Emotions of attribution: attributed responsibility to the agents about their actions based on rules.

- Emotions of attraction: based on attitudes toward objects.

The intensity of emotions can be affected by so-called local and global variables. Thus cognitive representations of emotions are also modified.

The local variables are variables that affect only one kind of emotion, for example, in the case of emotions based on events; the local variable that affects its intensity is the desirability of events and their consequences in relation to the goals. For attribution emotions, the corresponding local variable is the plausibility (approval or disapproval) of the agent's actions according to the rules. Finally Attraction emotions are affected in their intensity by the attraction of the objects.

Global variables, as the name implies, are variables that affect the intensity of all kinds of emotion and therefore, cognitive representation. These variables are: 1) proximity: it attempts to reflect the psychological proximity (in time or space) of event, object or agent that induces emotion, 2) sense of reality refers to the degree to which the event, agent or object underlying the affective reaction seems real to the person experiencing the emotion, 3) excitation: the existing level of arousal affects the intensity of emotions and thus their affective reaction and 4) the unexpected: refers to unexpected positive things are evaluated more positively than expected and unexpected negative things more negatively than expected.

Goals are classified according to OCC theory [4] in active pursuit goals (AGs), goals of interest (IGs) and filling goals (FGs). AGs represent the kind of things you want to get done and include goals set by Schank and Abelson (1977) named achievement goals (for obtain certain things), entertainment goals (to enjoy certain things), instrumental goals (are the instrument for other goals) and goals of crisis (to handle crises when preservation goals are threatened). IGs represent the kind of thing you want to happen and thus can generate AGs to encourage happen. IGs include preservation goals (to preserve certain states of affairs). FGs are cyclical, even if achieved, not abandoned. These goals include those established by Schank and Abelson (1977) like satisfaction goals (meet certain requirements). In case OCC theory, needs can be biological or otherwise be cyclical.

To emulate the perception of emotions during the ILSuser interaction, it is considered a pedagogical agent designed with an affective-motivational cognitive structure. Integrated, this latter, to the ILS inference engine [5-10]. The affective-motivational cognitive structure is built according to the OCC theory and the implementation of this structure is realized through FCM [11-15].

\section{Fuzzy Cognitive Maps (FCM)}

The fuzzy cognitive maps (FCM) were introduced by Bart Kosko [16] to describe the behavior of a system in terms of concepts and causal relationships between these concepts. Digraphs FCM are used to represent causal reasoning in which the nodes are concepts that describe the main features of the system, and the edges between nodes establish causal relationships between the concepts. The diffuse part allows degrees of causality in relationships. FCMs are used as representation technique, due to its ability to handle inherent uncertainty in the decision making processes complex, and having a parallel and distributed reasoning [17].

The qualitative approach of the relationship matrix allows us to observe the behavior of the system. However, you must have a quantification and interpretation with respect to causation of FCM. This quantification allows for the next state of each node, by adding effects to all nodes on the particular node $[13,14,18]$.

\section{Causality Relationships}

Causality relationships refer to the effect that a concept has on the rest of the concepts involved in the description of an environment. The effect is to increase or decrease the likelihood of occurrence of another concept. Therefore, there are two types of relationships: negative and positive.

- Negative: the negative relationship is one in which the increase in the likelihood of occurrence of an element causes the proportional decrease in the likelihood of occurrence of another element. And the decrease in one causes the proportional increase of other. Is expressed numerically by taking a value within the range $[-1,0)$.

- Positive: the positive relationship is one in which an increase in the likelihood of occurrence of an element causes proportional increase in the likelihood of occurrence of another element and a decrease in the likelihood of one causes the proportional decrease in the likelihood of occurrence of other. For example, increasing errors originates increased likelihood of occurrence of frustration. Is expressed numerically by 
taking values in the range $(0,1]$.

- If there is no effect or it is neutral, the relationship is expressed as 0 (zero).

\section{Interface Design: A Pedagogical Agent}

Emotive pedagogical agents are the last generation to design human-computer interfaces. This kind of agents is different because their appearance more accurately simulates an animated character or even a human. They have a guide on how applications and conventions should be their personality and appearance. Pedagogical agents are created to support learning by interacting with students in interactive learning environments $[19,20]$.

The credibility of these agents build trust relies on the visual quality of the agent and the behaviors that emulate humans [21,22].

Animated pedagogical agents facilitate learning in computer environments. These agents represent animated characters that respond to actions taken by the user. Furthermore, there is the mode where the latter have the ability to move within the context of learning, thus providing useful functions within learning environments [23].

A pedagogical agent can be invaluable for the user knowing whether their actions are inappropriate or incorrect, in which case the agent can intervene. Pedagogical agents show entertaining speeches during the teaching-learning process and can intervene with tips, tactics didactic introductions and even attention calls [1,24].

The layout design consists of six phases: the Case, is where you define the user profile and from it creates the most suitable interface design, including pedagogical agent prototype, in Problem analyzing user requirements individually, in this case we use learning styles as a guideline, in Hypothesis are the profiles created by combining learning styles and color and how these can be represented graphically, for the Project is selected the most viable option and create models according to the specifications in a program for this purpose, in Performing, animations are developed and inserted into the interface, and finally in the Evaluation end user is used for use the interface and provide their comments [25].

\section{Affective-Motivational Interface of a Pedagogical Agent}

Figure 1 shows the affective-motivational interface of agent designed according to user preferences. These preferences are identified through a questionnaire which asked users about the physical characteristics of a pedagogical agent. The actions undertaken by the pedagogical agent are based on actions of the inference engine designed on an affective-motivational cognitive structure representing the TLP $[10,12]$.

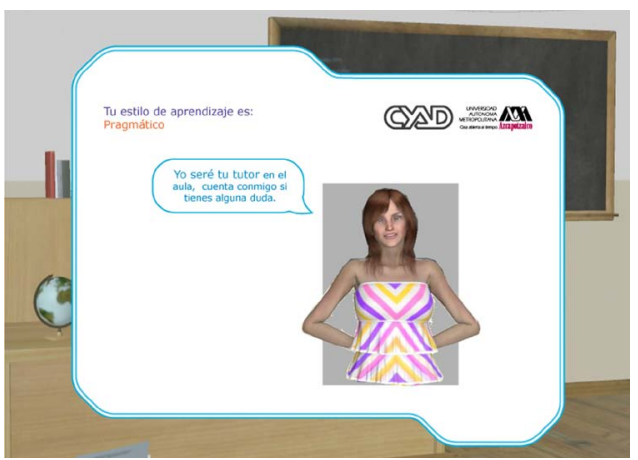

Figure 1. Affective pedagogical agent.

\section{Affective-Motivational Structure}

The affective-motivational structure (Figure 2) shows the concepts involved in the TLP, such as goals, events, actions of user or agent, rules and affects. These concepts are tied to the TLP elements through facets of motivation such as: effort, latency, persistence, and choice.

Interest and desire, for example, are especially related to persistence and effort. Joy, admiration, pride, and the like, for their part, provide the energy of motivation. Help is related to choice, and relief affect feeds this choice.

Strategies are actions based on an instructional goal emerged as a top goal in the affective-motivational structure. Therefore, these strategies are called instructional strategies. Instructional strategies can be cognitive and operative. Cognitive strategies are actions of the cognitive diagnosis and Operative strategies are appropriate actions to drive the instruction, so include strategies to contextualize, to guide, motivate and retain the user's attention [24].

To link operative strategies to the affective-motivational structure is necessary to define the actions to take in each instructional level related to the type of knowledge or skill involved in the proposed task to achieve instructional objectives [12]. The actions for each instructional level are listed according to information and portrayal that are consistent for each category of generalizable skill (learning category). The strategy is chosen according to the type of user error, instructional level, learning category and inferred affect.

Nomenclature of TLP elements:

\begin{tabular}{lcl}
\hline ID Interest \& Desire & E & Errors \\
H Help & JP & Joy-Pride \\
St Strategies & AL & Admiration-Like \\
I Interruption & R & Relief \\
Q Quit & DR & Dislike-Reproach \\
P Performance & FA & Frustration-Anguish \\
L Latency & Sh & Shame \\
\hline
\end{tabular}




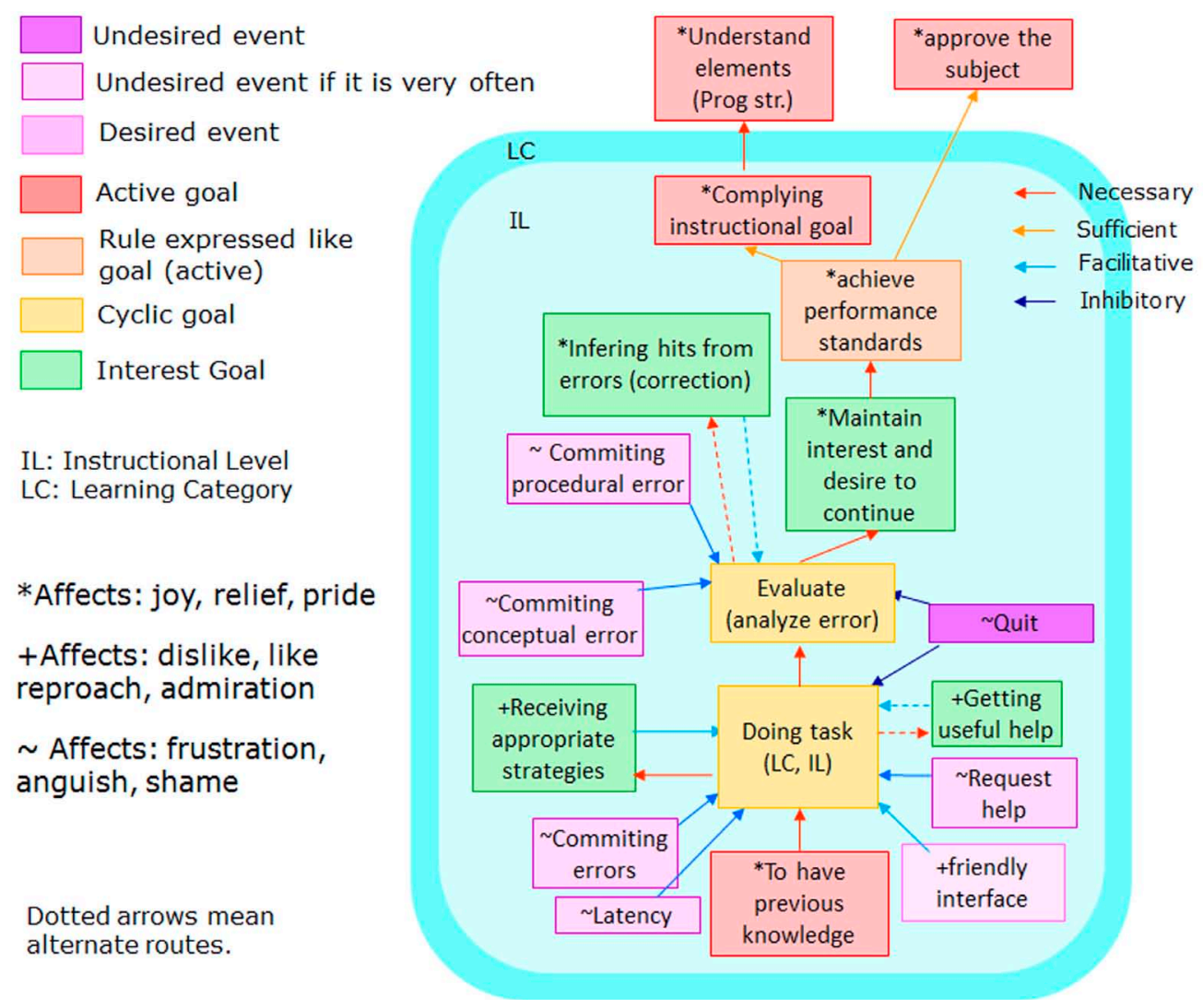

Figure 2. Affective-motivational structure.

\subsection{Causality Relationships in the Affective-Motivational Structure}

TLP elements are interrelated through causality relationships that indicate the effect that an element has on the rest of the elements involved in the description of an environment. The effect is to increase or reduce the likelihood of another element appearing. So there are negative and positive relationships (Table 1 ).

For example, the ID, according to affective-motivational model, is positively related to JP, AL and P. This means that an increase in the likelihood of occurrence of ID causes the proportional increase in the likelihood of occurrence of JP, AL and P. Otherwise, a decrease in the likelihood of occurrence of ID causes the proportional decrease in the likelihood of occurrence of JP, AL and P.

On the other hand, ID is negatively related to Q, E and DR. This means that an increase in the likelihood of occurrence of ID causes the proportional decrease in the likelihood of occurrence of Q, E and DR. Otherwise, a decrease in the likelihood of occurrence of ID causes the proportional increase in the likelihood of occurrence of $\mathrm{Q}$, E and DR.

\subsection{Causality Matrix}

The relationships are represented in a matrix of causali-
Table 1. Causality relationships.

\begin{tabular}{|c|c|c|}
\hline & Relationship & Related concepts \\
\hline ID & $\begin{array}{l}\text { Positive } \\
\text { Negative }\end{array}$ & $\begin{array}{l}\text { JP, AL, P } \\
\text { Q, E, DR }\end{array}$ \\
\hline $\mathrm{H}$ & $\begin{array}{l}\text { Positive } \\
\text { Negative }\end{array}$ & $\underset{E}{R, ~ S t, ~ I, ~ L ~}$ \\
\hline St & $\begin{array}{l}\text { Positive } \\
\text { Negative }\end{array}$ & $\begin{array}{l}\text { AL, ID, P } \\
\text { DR, Q, E }\end{array}$ \\
\hline I & $\begin{array}{l}\text { Positive } \\
\text { Negative }\end{array}$ & $\begin{array}{l}\text { St, Q } \\
\text { ID }\end{array}$ \\
\hline Q & $\begin{array}{l}\text { Positive } \\
\text { Negative }\end{array}$ & $\begin{array}{c}\text { FA, Sh, E } \\
\text { JP, AL, R, ID, St, P }\end{array}$ \\
\hline $\mathrm{P}$ & $\begin{array}{l}\text { Positive } \\
\text { Negative }\end{array}$ & $\begin{array}{c}\text { JP, AL, R, ID, St } \\
\text { I, Q, L, E, DR, FA, Sh }\end{array}$ \\
\hline $\mathrm{L}$ & $\begin{array}{l}\text { Positive } \\
\text { Negative }\end{array}$ & $\begin{array}{l}\text { St, I } \\
\text { R, P }\end{array}$ \\
\hline $\mathrm{E}$ & $\begin{array}{l}\text { Positive } \\
\text { Negative }\end{array}$ & $\begin{array}{l}\text { FA, Sh, St, I, Q } \\
\text { ID }\end{array}$ \\
\hline JP & $\begin{array}{l}\text { Positive } \\
\text { Negative }\end{array}$ & $\begin{array}{l}\text { ID, P, AL } \\
\text { L, E, DR }\end{array}$ \\
\hline $\mathrm{AL}$ & $\begin{array}{l}\text { Positive } \\
\text { Negative }\end{array}$ & $\begin{array}{c}\text { ID, St, } \\
\text { Q, L, DR }\end{array}$ \\
\hline $\mathrm{R}$ & $\begin{array}{l}\text { Positive } \\
\text { Negative }\end{array}$ & $\begin{array}{l}\text { St, P } \\
\text { Q, FA }\end{array}$ \\
\hline DR & $\begin{array}{l}\text { Positive } \\
\text { Negative }\end{array}$ & $\begin{array}{c}\text { St, I, Q, L, E, FA, Sh } \\
\text { ID, P, AL, R }\end{array}$ \\
\hline FA & $\begin{array}{l}\text { Positive } \\
\text { Negative }\end{array}$ & $\begin{array}{c}\text { Q, E, L, DR, Sh } \\
\text { P, JP, AL, R }\end{array}$ \\
\hline Sh & $\begin{array}{l}\text { Positive } \\
\text { Negative }\end{array}$ & $\begin{array}{l}\text { St, Q, E, DR, FA } \\
\text { ID, P, JP, AL }\end{array}$ \\
\hline
\end{tabular}


ties (Table 2) based on the description of the positive and negative relationships.

Causality matrix forms the agent's inference engine. The inference engine response is the next state of each of the elements of the model and is obtained by multiplying an input vector (state values of the elements that constitute the affective-motivational model) by the matrix of causality. The resulting vector (output vector) is evaluated using the logistic function (Equation (1)) as threshold function [16]. This is repeated until a stable output vector.

$$
s(x)=1 /\left(1+\mathrm{e}^{-c x}\right)
$$

where:

$S(x)=$ Logistic function, and represents the bounded output vector.

$x=$ output vector resulting from multiplying the input vector by the causality matrix and represents the sum of effects between the elements of the motivational-affective model.

$\mathrm{c}=$ scaling constant $=5$.

The logistic function takes the dimension of the result in the range $[0,1]$. So that it enables us to interpret each of the vector values as the likelihood that respective motivational-affective model element is present $[13,14,18]$.

\section{Tests and Results}

The prototype of intelligent learning system (ILS) is designed with an inference engine that includes the affective-motivational model (based on affective-motivational structure).

Table 2. Causality matrix.

\begin{tabular}{ccccccccccccccc}
\hline & ID & H & S & I & Q & L & Lt & E & JP & AL & R & HR & DF & Sh \\
\hline ID & 0 & 0 & 0 & 0 & -1 & 1 & 0 & -1 & 1 & 1 & 0 & -1 & 0 & 0 \\
H & 0 & 0 & 1 & 1 & 0 & 0 & 1 & -1 & 0 & 0 & 1 & 0 & 0 & 0 \\
S & 1 & 0 & 0 & 0 & -1 & 1 & 0 & -1 & 0 & 1 & 0 & -1 & 0 & 0 \\
I & -1 & 0 & 1 & 0 & 1 & 0 & 0 & 0 & 0 & 0 & 0 & 0 & 0 & 0 \\
Q & -1 & 0 & -1 & 0 & 0 & -1 & 0 & 1 & -1 & -1 & -1 & 0 & 1 & 1 \\
L & 1 & 0 & 1 & -1 & -1 & 0 & -1 & -1 & 1 & 1 & 1 & -1 & -1 & -1 \\
Lt & 0 & 0 & 1 & 1 & 0 & -1 & 0 & 0 & 0 & 0 & -1 & 0 & 0 & 0 \\
E & -1 & 0 & 1 & 1 & 1 & 0 & 0 & 0 & 0 & 0 & 0 & 0 & 1 & 1 \\
JP & 1 & 0 & 0 & 0 & 0 & 1 & -1 & -1 & 0 & 1 & 0 & -1 & 0 & 0 \\
AL & 1 & 0 & 1 & 0 & -1 & 0 & -1 & 0 & 0 & 0 & 0 & -1 & 0 & 0 \\
R & 0 & 0 & 1 & 0 & -1 & 1 & 0 & 0 & 0 & 0 & 0 & 0 & -1 & 0 \\
HR & -1 & 0 & 1 & 1 & 1 & -1 & 1 & 1 & 0 & -1 & -1 & 0 & 1 & 1 \\
DF & 0 & 0 & 0 & 0 & 1 & -1 & 1 & 1 & -1 & -1 & -1 & 1 & 0 & 1 \\
Sh & -1 & 0 & 1 & 0 & 1 & -1 & 0 & 1 & -1 & -1 & 0 & 1 & 1 & 0 \\
\hline & & & & & & & & & & & & & & \\
\hline
\end{tabular}

The ILS is tested a first group of college students enrolled in structured programming (application domain). The tests consist of solving scenarios representative of application domain teaching-learning process.

Scenarios are tasks classified according to learning category and instructional level corresponding with the instructional objectives of structured programming.

Performance results are compared with those obtained by a second group of college students who used the ILS designed with an inference engine excluding the affective-motivational model. The results are summarized in the graph of Figures 3(a) and (b).

The results obtained with the ILS which included an affective-motivational model, improved by $6 \%$ compared to those obtained with the ILS did not include the model.

\section{Conclusions}

The contribution of this work to affective computing lies in the model used to choose strategies (FCM). This model can provide approximate answers to what happens in

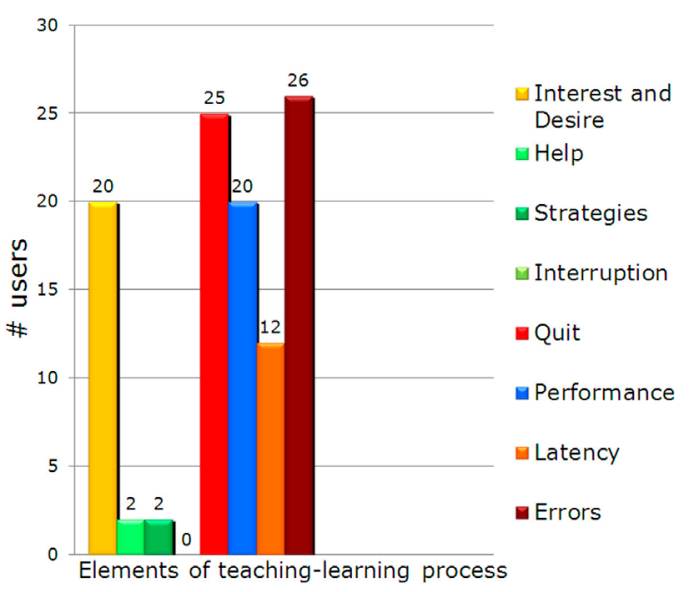

(a)

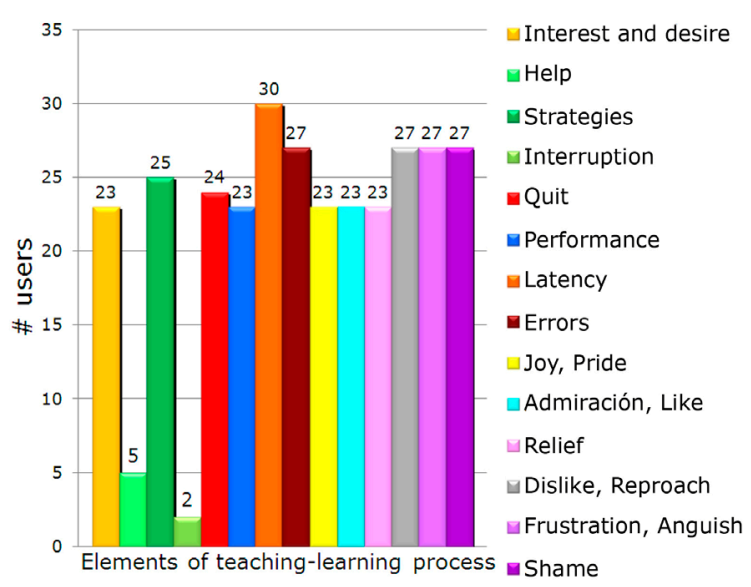

(b)

Figure 3. (a) ILS without affective-motivational model; (b) ILS with affective-motivational model. 
the environment with the cognitive and affective state of the user due to the parallel distribution of causality. This improves the user interaction with the system.

FCM modeling the behavior exhibited in the strategies related to the cognitive affective-motivational structure.

This structure feeds the student and the tutor modules, to which it provides clues to the user's emotional state. This helps in choosing the affective-cognitive strategy that the pedagogical agent will deploy, thereby maximizing the effectiveness of the intervention.

\section{Acknowledgements}

This paper is part of the research being carried out by Martha Mora-Torres to obtain her $\mathrm{PhD}$ in the Posgrado en Ciencia e Ingeniería de la Computación at the Universidad Nacional Autónoma de México. It is supported by CONACYT (CVU: 167259). Also, this project is part of the Soft Computing and Applications research (Emotions), funded by Universidad Autónoma Metropolitana.

\section{REFERENCES}

[1] A. L. Laureano-Cruces, “Agentes Pedagógicos,” Memorias XVII Congreso Nacional y III Congreso Internacional de Informática y Computación de la ANIEI, Tepic, 20-22 October 2004.

http://ce.azc.uam.mx/profesores/clc/02_publicaciones/mat erial/AgentesPedagogicos ANIEI04.pdf

[2] A. L. Laureano-Cruces, J. Ramírez-Rodríguez, F. de Arriaga and R. Escarela-Pérez, "Agents Control in Intelligent Learning Systems: The Case of Reactive Characteristics," Interactive Learning Environments, Vol. 14, No. 2, 2006, pp. 95-118. http://dx.doi.org/10.1080/10494820600769049

[3] K. R. Scherer, "Psychological Models of Emotion,” In: J. C. Borod, Ed., The Neuropsychology of Emotion, Oxford University Press, New York, 2000, pp. 137-162. http://emotion.caltech.edu/dropbox/bi133/files/Psycholog ical.pdf

[4] A. Ortony, G. Clore and A. Collins, "The Cognitive Structure of Emotions," Cambridge University Press, Cambridge, 1988. http://dx.doi.org/10.1017/CBO9780511571299

[5] A. Laureano-Cruces, "Emociones Sintéticas y Avatars," En el Libro: De la Reflexión a la Acción, Editado por la División de Ciencias y Artes para el Diseño, 2006, pp. 251-255.

http://ce.azc.uam.mx/profesores/clc/04_proyecto_de_inv/ comp_suave/EmocionesSint.pdf

[6] A. L. Laureano-Cruces, P. Velasco-Santos, M. MoraTorres and D. Acevedo-Moreno, "Hacia Interfaces Inteligentes,” Libro Científico: Avances de las Mujeres en las Ciencias, las Humanidades y Todas las Disciplinas, Sustentabilidad, Aire, 2009, pp. 237-246.

[7] A. L. Laureano-Cruces and E. Hegmann-González, "Maze Videogame that Adapts to the User's Emotions According to his Behavior," ICGST-Artificial Intelligence Ma- chine Learning Journal, Vol. 11, No. 2, 2011, pp. 21-25. http://www.icgst.com/paper.aspx?pid=P1121102462

[8] A. L. Laureano-Cruces and A. Rodríguez-García, "Design and Implementation of an Educational Virtual Pet Using the OCC Theory," Journal of Ambient Intelligence and Humanized Computing, Vol. 3, No. 1, 2012, pp. 61-71. http://dx.doi.org/10.1007/s12652-011-0089-4

[9] A. L. Laureano-Cruces, D. Acevedo-Moreno, M. MoraTorres and J. Ramírez-Rodríguez, "A Reactive Behavior Agent: Including Emotions for a Video Game,” Journal of Applied Research and Technology, Vol. 10, No. 5, 2012, pp. 651-672. http://www.redalyc.org/articulo.oa?id=47425122001

[10] M. Mora-Torres, A. L. Laureano-Cruces and P. VelascoSantos, "Estructura de las Emociones dentro de un Proceso de Enseñanza-Aprendizaje,” Revista Perfiles Educativos-UNAM, Vol XXXIII, No. 131, 2011, pp. 64-79. http://www.redalyc.org/articulo.oa?id=13218531005

[11] M. S. Khan, A. Chong and M. Quaddus, "Fuzzy Cognitive Maps and Intelligent Decision Support-A Review," School of Information Technology, Murdoch University, Graduate School of Business, Curtin University of Technology, 1987.

http://wawisr01.uwa.edu.au/1999/khanchongquaddus.pdf

[12] A. L. Laureano-Cruces, M. Mora-Torres, J. Ramírez-Rodríguez and F. De Arriaga-Gómez, "Operative Strategies Related to an Affective-Motivational Architecture to Achieve Instructional Objectives,” ICGST-Artificial Intelligence Machine Learning Journal, Vol. 11, No. 2, 2011, pp. 15-20.

http://www.icgst.com/paper.aspx?pid=P1121139825

[13] M. Mora-Torres, "Sistema Experto en la Toma de Decisiones de un Escenario de Riesgo: LOCA Pequeño en una Planta Nucleoeléctrica," MSc. Degree Thesis, Posgrado en Ciencia e Ingeniería de la ComputaciónUniversidad Nacional Autónoma de México, 2007. http://ce.azc.uam.mx/profesores/clc/02_publicaciones/tesi s_dirigidas/MIC_Mora_Torres_Martha.pdf

[14] M. Mora-Torres, A. L. Laureano-Cruces, J. Ramírez-Rodríguez and G. Espinosa-Paredes, "Analysis and Design of the Representation of the Knowledge for the Implementation of a Distributed Reasoning," Revista de Matemática: Teoría y Aplicaciones, Vol. 16, No. 2, 2009, pp. 267-281.

http://www.latindex.ucr.ac.cr/mate-16-2/matematica-16-2 -07.pdf

[15] C. E. Peláez and J. B. Bowles, “Applying Fuzzy Cognitive Maps Knowledge-Representation to Failure Modes Effects Analysis,” IEEE Proceedings Annual Reliability and Maintainability Symposium, Washington DC, 16-19 January 1995, pp. 450-456. http://dx.doi.org/10.1109/RAMS.1995.513283

[16] B. Kosko, “Fuzzy Cognitive Maps,” International Journal of Man-Machine Studies, Vol. 24, No. 1, 1986, pp. 65-75. http://dx.doi.org/10.1016/S0020-7373(86)80040-2

[17] A. Konar and L. Jain, "Cognitive Engineering: A Distributed Approach to Machine Intelligence,” Springer Verlag, London, 2005. 
http://dx.doi.org/10.1007/1-84628-234-9

[18] A. L. Laureano-Cruces, J. Ramírez-Rodríguez, M. MoraTorres and G. Espinosa-Paredes, "Modeling a Decision Making Process in a Risk Scenario: LOCA in a Nucleoelectric Plant Using Fuzzy Cognitive Maps,” Research in Computing Science, Vol. 26, 2006, pp. 3-13. http://www.micai.org/rcs/Vol26.pdf

[19] M. Nunes, L. Dihl, L. Fraga, C. Woszezenki, L. Oliveira, D. Francisco, G. Machado, C. Nogueira and M. Notargiacomo, "Animated Pedagogical Agent in the Intelligent Virtual Teaching Environment,” Interactive Educational Multimedia, Vol. 4, 2002, pp. 53-61.

http://greav.ub.edu/der/index.php/der/article/download/46 $\underline{134}$

[20] P. Velasco-Santos, A. L. Laureano-Cruces, M. MoraTorres and L. Sánchez-Guerrero, "La Importancia del Diseño de una Interfaz en el Proceso de EnseñanzaAprendizaje," Proceedings of XXI Congreso Nacional y VII Congreso Internacional de Informática y Computación de la ANIEI, Monterrey, 1-3 October 2008, pp. 108-113. http://ce.azc.uam.mx/profesores/clc/

[21] P. Jacques and R. M. Vicari, “A BDI Approach to Infer Student's Emotions in an Intelligent Learning Environment," Computers \& Education, Vol. 49, No. 2, 2007, pp. 360-384. http://dx.doi.org/10.1016/j.compedu.2005.09.002

[22] J. C. Lester and B. A. Stone, "Increasing Believability in Animated Pedagogical Agents," Memories Autonomous Agents, Vol. 97, Marina del Rey, 1997, pp. 16-21. http://dx.doi.org/10.1145/267658.269943

[23] W. L. Johnson, E. Shawand R. Ganeshan, "Pedagogical Agents on the Web," Proceedings of the 3rd International Conference on Autonomous Agents, New York, 1-5 May 1999, pp. 283-290. http://dx.doi.org/10.1007/3-540-45490-X 4

[24] A. L. Laureano-Cruces, J. Ramírez-Rodríguez, M. MoraTorres, F. De Arriaga and R. Escarela-Pérez, "CognitiveOperative Model of Intelligent Learning Systems Behavior,” Interactive Learning Environments, Vol. 18, No. 1, 2010, pp. 11-38. http://dx.doi.org/10.1080/10494820802160872

[25] P. Velasco-Santos, L. Sánchez-Guerrero, A. L. LaureanoCruces and M. Mora-Torres, "Un Diseño de Interfaz: Tomando en Cuenta los Estilos de Aprendizaje,” Memoria XXII Congreso Nacional y VIII Congreso Internacional de Informática y Computación de la ANIEI, Ensenada, Baja, 21-23 October 2009, pp. 311-320. http://ce.azc.uam.mx/profesores/clc/02 publicaciones/mat erial/InterfazYColor.pdf 